\title{
Kosmische Wurmlöcher in die Ewigkeit
}

\section{Christina Aus der Au}

Prof. Dr. theol., Mitglied der Redaktion Ethik

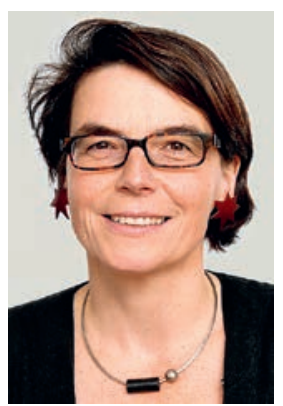

Ich sass mit einigen anderen auf der Terrasse der Jugendherberge. Wir hatten einen intensiven Tag hinter uns. Wir waren aus unterschiedlichen Ländern zusammengekommen für einen Workshop, hatten Wissen und Erfahrungen ausgetauscht, gepowerpointet, diskutiert, organisiert, geplant.

Und jetzt war es Abend geworden, ein warmer Sommerabend, wir sassen draussen, und mein ungarischer Nebenmann teilte seine Flasche Wein mit mir. Die Welt war perfekt. Ein Franzose zog eine Packung Zigarillos aus der Tasche. Diejenigen mit Pfeifentabak, die ich in meinen Jugendjahren auch gelegentlich geraucht hatte. Und da überkommt es mich. «Darf ich Dir eine ausreissen?» Er hält mir seine Packung entgegen und ich klaube eine heraus. Zünde sie am Streichholz an, das er mir entgegenhält. Ziehe ein, kein Lungenzug, aber ich spüre den Geschmack im Gaumen, halte ihn im Mund und atme ihn langsam wieder aus. Ich grinse über die erstaunten Gesichter rundherum. Blase Rauchringe in die Nachtluft. Die Welt ist perfekt.

Am anderen Morgen beim Aufwachen spüre ich nicht nur die kurze Nacht, sondern vor allem den kalten Rauch in meinem Rachen. Bäh, das ist ja noch schlimmer als Knoblauch gegessen zu haben am Abend zuvor. Was hat mich denn gestern geritten? Ich bin nun wirklich zu alt, um jetzt aus heiterem Himmel mit dem Rauchen anzufangen. Ich muss nicht mehr cool wirken, noch muss ich beweisen, dass ich irgendwo dazugehöre. Ich habe keinen Glimmstengel nötig, um meine Hände zu beschäftigen und auch nicht, um mit anderen ins Gespräch zu kommen. Rauchen ist teuer und bescheuert ungesund.

Aber hier war es einfach nur schön. Es hat gepasst. Wir hatten vorher über Gott und die Welt diskutiert, über Kirche und Gesellschaft, in Polen, Rumänien, Ungarn, England, den USA. Über Klimaerwärmung und Migration, und über den wachsenden Graben zwischen Arm und Reich. Es hängt alles mit allem zusammen, und was können wir schon tun? Obwohl wir ja etwas tun wollen, uns zusammenschliessen, die europäische Zivilgesellschaft stärken, über die Grenzen hinaus im Gespräch bleiben. Aber es ist schon verflixt komplex und kompliziert.

Und so versuchen wir wenigstens in unseren eigenen Leben etwas auf den Weg zu bringen, wenn wir schon nicht die Welt verändern können. Einige meiner
Freunde sind vegan geworden. Keine tierischen Produkte mehr, keine Milch, keine Eier, kein Leder. Aus plausiblen Gründen, die Gesundheit, die Ökologie, die Klimaerwärmung, das Tierleiden. Dagegen spricht die regionale Landwirtschaft, unsere Kultur, die Importprodukte. Und auch die Gesundheit, sagen die anderen. Aber wenigstens Bio, fair trade, aus der Region. Soll man darüber frei entscheiden können oder soll es gesetzlich geregelt werden? Und schon wird auch das wieder überwältigend komplex.

Und da hat mein Kollege die Zigarillos hervorgezogen. Ein herrlich einfacher, wunderbar sinnfreier Moment von «jetzt ist jetzt». Vergangenheit, Gegenwart und Zukunft schnurren auf einen Punkt zusammen. Wir. Hier. Jetzt. Schön.

Sich zwischendurch so einen Moment ausklinken zu können, bewahrt, so glaube ich, jedenfalls mich vor dem geistigen und emotionalen Überwältigt- und Überfordertsein. Ich habe einige grössere und kleinere Strategien für solche Ausklinkmomente: kurz in den Garten gehen, Tee trinken, Katze streicheln, Solitaire spielen ... all diese Dinge, mit denen man Ernsthaftes und Schwieriges etwas hinausschieben kann. Oft genug ist es eben einfach Prokrastination, wie das Mode gewordenen Fachwort heisst. Morgen, morgen, nur nicht heute ... und dann kommt man zurück, und nichts hat sich geändert, nur die deadline ist noch ein wenig näher gerutscht. Und manchmal ist so ein Moment auch mehr. Manchmal rutscht man damit wie durch ein kosmisches Wurmloch in die Ewigkeit hinein. Die Gegensätze fallen im Erleben zusammen: fremd-vertraut, einfach-komplex, gut-schlecht, vergangen-zukünftig. Es ist, wie es ist, sagt der Moment.

Allerdings nicht ganz ungefährlich - dann nämlich, wenn dabei vielleicht langfristige Konsequenzen angestossen werden. Der Temporausch. Der Drogenkonsum. Der Seitensprung. Erfahrungen, die wohl ähnlich ewigkeitsberauschend daherkommen.

Da war mein Zigarillo harmlos dagegen. Am nächsten Abend wollte ich es wiederholen. Der Kollege hat mir wieder eins angeboten. Und ich hab angezündet, eingezogen, ausgeblasen. Es war nett, aber nicht annähernd so metaphysisch wie am Abend zuvor. Kosmische Wurmlöcher lassen sich nicht auf Verlangen herstellen. 